\title{
TRES DISTINTOS MAYTAS Y UN SOLO VARGAS LLOSA
}

\section{Horacio Castellanos Moya}

\begin{abstract}
Historia de Mayta — advierte Horacio Castellanos en este artículo - fue la primera novela de Mario Vargas Llosa que recibió una lectura e interpretación por parte de críticos y lectores que no reflejaba las ideas rectoras a partir de las cuales el autor habría escrito el libro. La crítica entendió la obra como una novela eminentemente política contra los planteamientos revolucionarios en el Perú y en Latinoamérica. Sin embargo, en entrevistas y artículos Vargas Llosa defendió otra lectura a partir de sus concepciones sobre la ficción. Pero quizá el cuerpo más organizado de ideas sobre Historia de Mayta fue la conferencia que ofreció Vargas Llosa en la Universidad de Syracuse en 1988. En este ensayo se sostiene que el texto de esa conferencia, casi desconocido por el público hispanohablante, escrito originalmente en inglés y publicado como un capítulo del libro $A$ Writer's
\end{abstract}

Horacio Castellanos Moya. Escritor y periodista salvadoreño. Su primera novela, La diáspora, mereció el Premio Nacional otorgado por la Universidad Centroamericana “José Simeón Cañas” de San Salvador en 1989. Su novela más reciente es La sirvienta y el luchador (Tusquets, 2011). Trabajó doce años como periodista en Ciudad de México. Desde 2006 reside en Estados Unidos. Ha sido profesor invitado en el Writing Program de la Universidad de Pittsburgh, e Ida Cordelia Beam Distinguished Visiting Professor de la Universidad de Iowa. Hc.moya@yahoo.com.

Estudios Públicos, 122 (otoño 2011). 
Reality, revela las motivaciones y búsquedas de Vargas Llosa, el proceso de creación con todas sus complejidades, como también con sus contradicciones y claroscuros.

1. $C_{\text {uando finalizaba sus estudios en la Universidad de San }}$ Marcos, en Lima, Mario Vargas Llosa descubrió la obra de William Faulkner, el primer escritor al que leyó "con papel y lápiz, tratando de descifrar las estructuras y los aspectos formales de sus novelas"1. No es difícil imaginar al joven aprendiz de escritor desmontando con asombro las obras del novelista sureño, de quien aprendió "que la forma puede ser un personaje en una novela y a veces el personaje más importante, a través de la organización de la perspectiva de la narración, del uso de diferentes narradores, de la retención de información para crear ambigüedad". Vargas Llosa estaba "fascinado con el extraordinario dominio de la estructura" que descubrió en Faulkner, de inmediato puso en práctica lo descubierto y desde entonces no ha dejado de ser un apasionado malabarista y renovador de las técnicas narrativas.

2. Si bien es fácil imaginar al joven Vargas Llosa en la faena del desmontaje de la saga de Yoknapatawpha, resulta imposible imaginar a otro inmenso descendiente de Faulkner, Juan Carlos Onetti, abocado a esa tarea. Dime cómo lees a tu maestro y te diré el tipo de escritor que eres. El uruguayo asimiló por ósmosis, empatía con ese mundo de perdedores, con esa forma sinuosa de contar la derrota, en tanto que el peruano estudiaba los mecanismos, lo que antes hubiéramos llamado "la carpintería" de la obra artística. Lo paradójico es que el mismo Faulkner dijo en su famosa entrevista con el Paris Review, en 1956, que "si un escritor está interesado en la técnica, dejémoslo que se dedique a la cirugía o a la albañilería", y añadió que "no hay una ruta mecánica para la escritura, no hay atajos, y el joven escritor sería un tonto si sigue una teoría"2.

${ }^{1}$ Las citas de este párrafo han sido tomadas de Mario Vargas Llosa, $A$ Writer's Reality, 1991, capítulo "Discovering a Method for Writing”. La traducción es de mi responsabilidad.

${ }^{2}$ William Faulkner, “The Art of Fiction”, 1956. 
3. Vargas Llosa no era, claro está, un tonto siguiendo a Faulkner, sino todo lo contrario. Desde sus inicios hasta su consagración final con el Premio Nobel, el peruano se ha regido por aquel principio faulkneriano de 99 por ciento talento, 99 por ciento disciplina, 99 por ciento trabajo. Y quizá sea el más racional de los escritores de su generación, el llamado "boom", no sólo el que analiza con mayor claridad el fondo y la forma de sus obras, sino el que trabaja a partir de esquemas muy definidos y que, según dice, siente más placer en la reescritura, en lo que es la talacha, que en la escritura original. Él mismo reconoce que nunca pudo comprender cómo su entonces amigo Julio Cortázar pudo escribir Rayuela sin seguir un plan acabado al detalle, nada más sentándose frente a la máquina de escribir y dejándose guiar por su intuición. $Y$ ese es el tipo de narrador que Vargas Llosa no es: espontáneo, intuitivo, improvisador como el jazzista que había en Cortázar.

4. Vargas Llosa es un narrador consciente de los impulsos originales que lo han llevado a escribir lo que ha escrito, del proceso de construcción de sus obras; un escritor al que no se le pierde la procedencia de la más pequeña materia narrativa que cae en sus manos, ni lo que hace con ella, ni cómo lo hace; un escritor acostumbrado a explicarse con lucidez y en detalle, y que pareciera dejar muy poco al misterio. Un par de años después de publicar su segunda novela, La casa verde (1966), Vargas Llosa se puso a trabajar en un texto en el que abordaba tanto los aspectos intrínsecos de la escritura de esa novela, como las experiencias personales de las que procedía y el contexto histórico en el que la produjo; el texto, escrito originalmente en inglés, fue leído en la Washington State University, y pocos años más tarde se publicó en español bajo el título de Historia secreta de una novela (Tusquets Editores, 1971). A diferencia de Thomas Mann, quien según el crítico Marcel Reich-Ranicki acostumbraba dictar a los reseñistas lo que estos tenían que resaltar de sus obras, Vargas Llosa se ha encargado él mismo de destacar lo que haya que destacar en sus novelas. Es su propio, y quizá principal, exégeta.

5. En abril de 1988, Vargas Llosa fue invitado a dar una serie de conferencias sobre su obra a la universidad de Syracuse, en el norte del estado de Nueva York. Los textos de esas charlas, escritos en inglés, fueron publicados posteriormente bajo el título de $A$ Writer's 
Reality (Houghton Mifflin Company, 1991, 164 pp.). Cosa curiosa: en la página legal se dice que "este libro fue publicado en lengua española bajo el título de La verdad de las mentiras". Error editorial o mentira sin verdad, el hecho es que ninguna de las charlas ofrecidas en la universidad estadounidense está incluida en La verdad de las mentiras, un libro en el que Vargas Llosa aborda las principales obras de la literatura mundial y no disecciona sus propias novelas, como sí lo hace en $A$ Writer's Reality.

6. Un hombre que escribe tanto, con una producción tan vasta, tiende a veces a hacer refritos, recocidos con materiales y sobrantes procedentes de otros guisos. Al menos tres de los ocho capítulos de $A$ Writer's Reality tienen ese origen: el que dedica a Borges ${ }^{3}$, el que dedica a las crónicas de la conquista del Perú ${ }^{4}$ y el ya mencionado que dedica a La casa verde, cuyo título inglés "On Being Nine and First Seeing the Sea" (Sobre tener nueve años y ver por primera vez el mar) no se parece en nada al original español Historia secreta de una novela. Los otros cinco capítulos corresponden a cada una de las otras novelas publicadas por Vargas Llosa en el periodo que va de 1963 a 1984, desde La ciudad y los perros hasta Historia de Mayta, con la excepción de Conversación en La Catedral, cuya ausencia no deja de llamar la atención, como si el escritor no hubiera estado listo aún para revelar ante los estudiantes y el público estadounidenses los intríngulis y secretos de su obra cumbre. En el abordaje de cada una de sus novelas, Vargas Llosa pone distintos énfasis: por ejemplo, en el capítulo sobre La ciudad y los perros, titulado "Discovering a Method for Writing" (El descubrimiento de un método para escribir), abunda en su aprendizaje de las técnicas narrativas ${ }^{5}$; en el dedicado a La guerra del fin del mundo, titulado "Author's Favorite" (La favorita del autor), su atención se concentra en los inmensos retos que tuvo que enfrentar al escribir su primera obra de ficción que no sucedía en el Perú ni en la época contemporánea.

${ }^{3}$ Conferencia titulada "Las ficciones de Borges", ofrecida en Londres con motivo del "Fifth Annual Jorge Luis Borges Lecture", e incluida en Contra viento y marea, 1990.

${ }^{4}$ Originalmente publicado en español en el periódico El País bajo el título "El nacimiento del Perú", el 13 de abril de 1986, e incluido en el mismo volumen de Contra viento y marea.

${ }^{5}$ De ese capítulo he tomado la cita sobre la influencia de Faulkner mencionada al principio de este artículo. 
7. El capítulo más llamativo es sin duda el último, dedicado a Historia de Mayta (1984), porque es en él que el escritor se emplea a fondo para desentrañar y explicar las motivaciones que lo llevaron a escribir esta novela, que para muchos marcó un cambio en la trayectoria narrativa de Vargas Llosa. Fue la primera novela que recibió fuertes palos de la crítica y los lectores por su contenido político, en el que se vio la transformación de un escritor de izquierda en un escritor de derecha, que escribía una novela fruto de su nuevo programa político, en un momento de extrema radicalización en el Perú, cuando la guerrilla maoísta Sendero Luminoso y el gobierno peruano se trenzaban en una guerra brutal, y las fuerzas de la izquierda moderada legal se veían arrasadas entre ambos fuegos. Vargas Llosa resintió la reacción de crítica y lectores, $\mathrm{y}$, hombre de rápidos reflejos, se dedicó a explicar, a través de entrevistas y artículos (como el famoso "El arte de mentir"), los objetivos literarios que perseguía con Historia de Mayta. No obstante, es en el último capítulo de $A$ Writer's Reality, titulado precisamente "Transforming a Lie into Truth" (Transformando una mentira en verdad), donde el autor sistematiza y expone con mayor prolijidad las intenciones que lo llevaron a escribir esa novela ${ }^{6}$.

8. Vargas Llosa comienza el texto quejándose de que ni siquiera sus editores estadounidenses hayan comprendido el sentido de su libro: la traducción del título, The Real Life of Alejandro Mayta (La verdadera vida de Alejandro Mayta), expresa "exactamente lo opuesto" de lo que él se proponía con la novela, que era contar la vida "ficticia e imaginaria" de Alejandro Mayta ${ }^{7}$. Que un escritor poco conocido y que trata de abrirse espacios en otras lenguas deba aceptar las arbitrariedades de los editores, en especial a la hora de traducir los títulos, es algo comprensible; pero que un autor consagrado, como ya lo era Vargas Llosa entonces, acepte un título que niega el sentido de su novela, es algo más difícil de entender. ¿No lo consultaron? ¿O por qué aceptó? Pero en castellano no hubo, por supuesto, problema con el título, que juega con los dos sentidos de la palabra historia (como disciplina de estudio y como relato), sino que el principal problema fue otro: "Con este libro tengo la sensación de haber escrito una novela percibida por los críticos y los

${ }^{6}$ La traducción de las partes del texto de Vargas Llosa citadas en este artículo es de mi responsabilidad.

7 Mario Vargas Llosa, "Transforming a Lie into Truth" [1988], 1991, p. 143 . 
lectores de una manera muy diferente a la que yo pensé. Mis metas, mis motivaciones en este libro no eran las que los lectores imaginaron. Y no estoy diciendo que los lectores y los críticos estaban equivocados; lo que estoy diciendo es que mi planeación deliberada de este libro, mi trabajo consciente mientras lo estaba escribiendo, fue menos importante que mi sentimiento inconsciente, mi intervención inconsciente" (pp. 143-144). Con su texto Vargas Llosa tratará de poner en claro sus metas, motivaciones, la planeación deliberada, el trabajo consciente; no sucederá lo mismo con su "sentimiento inconsciente", al que dedicará menos palabras.

9. El meollo del malentendido, según el autor, era el siguiente: "Historia de Mayta ha sido leído principalmente como un libro político y en muchos casos ha sido considerado un ensayo político acerca de la violencia, revolución, levantamientos, descontento social y revueltas en Latinoamérica; un planteamiento político disfrazado de novela, presentado en forma de novela, un libro en el que lo esencial es la descripción de una realidad objetiva e histórica. Esa no era, por supuesto, mi intención cuando lo escribí. Yo sabía que estaba utilizando asuntos políticos, ideología, algunos hechos y eventos históricos como materia prima en esta novela; pero mi objetivo era literario, no político" (p. 144). ¿Era Vargas Llosa tan ingenuo para suponer que críticos y lectores no harían una lectura eminentemente política de su novela o su pose de autor víctima de la incomprensión es nada más la estratagema para iniciar el desarrollo de su argumentación? Había al menos dos razones obvias para esperar que Historia de Mayta funcionaría como un laxativo político en quienes en ese entonces la leyeron. La primera, como ya mencioné, el momento histórico que vivía el Perú, caracterizado por la polarización y la ideologización extremas propias de un conflicto armado interno, cuando una novela política se lee desde la pasión política y no desde las intenciones literarias del autor. La segunda tenía que ver con la trayectoria de Vargas Llosa: ésta era la primera novela en que abordaba a la izquierda peruana como tema desde que el autor culminó su conversión política - y me gustaría decir metamorfosis, pero no es el término preciso, porque el movimiento fue pendular, de un extremo al otro, propio del converso - que lo llevó del marxismo al liberalismo, de simpatizar con el castrismo a apoyar algunas políticas de la administración Reagan hacia Latinoamérica. 
Ciertamente el proceso de conversión política de Vargas Llosa sucedió varios años antes de la publicación de Historia de Mayta, y tal como él explica en su texto, dio inicio a mediados de la década de los 60 , cuando el régimen cubano impuso medidas contrarias a la libertad de artistas y escritores, medidas que "desilusionaron" al autor peruano, se profundizó con el apoyo de Castro a la invasión soviética de Checoslovaquia y culminó a principios de los 70 , cuando el poeta cubano Heberto Padilla fue detenido por las autoridades, lo que llevó a la ruptura definitiva de Vargas Llosa con el castrismo (p. 145). Éste fue un proceso público, y se expresó sobre todo en los ensayos y artículos del autor, pero no en su obra narrativa: ni en Pantaleón y las visitadoras, ni en La tía Julia y el escribidor, ni en La guerra del fin del mundo se reflejaba la nueva visión del escritor sobre la izquierda en el Perú contemporáneo. Por eso Historia de Mayta fue leída con tanta expectación, porque venía a llenar ese vacío.

10. Luego de explicar con lucidez y contundencia las razones por las que la ficción no es el mejor vehículo para hacer planteamientos políticos sino el ensayo, Vargas Llosa pasa a contar el origen de la novela: cuándo y dónde se le ocurrió por vez primera, y cómo el proceso de añejamiento de la idea original se fue modificando a medida que sucedía lo que él llama su "evolución política". La historia es conocida: estaba el joven Vargas Llosa en París, un día de 1962, leyendo el periódico Le Monde, cuando descubrió una breve noticia en la que se informaba de un alzamiento armado en el Perú que había sido sofocado de inmediato por las autoridades. Al joven escritor, entonces entusiasta admirador de la revolución de Castro, le pareció insólito que un hecho de esa naturaleza tuviera lugar en el Perú, porque hasta entonces se consideraba que la lucha armada era inviable en su país. Y más le sorprendió que la asonada hubiera sido dirigida por un viejo trotskista y un joven teniente, cuya tropa consistía en una veintena de adolescentes. La noticia, dice Vargas Llosa, removió sus recuerdos de cuando había sido militante comunista en sus años estudiantiles en Lima y "tal como sucedió con otros incentivos para escribir, pronto se convirtió en materia para la especulación literaria, algo sobre lo que mi imaginación y mi fantasía comenzaron a trabajar" (p. 145). Tiempo después el escritor se encontró con un peruano que tenía información más detallada sobre el alzamiento, de cómo la acción había sido preparada y organizada, y su interés 
creció, en especial porque en esa época era inconcebible un joven oficial militar con intenciones revolucionarias de corte marxista y también porque en vez de que Mayta reclutara al teniente para incorporarlo a su grupo trotskista, fue el teniente quien reclutó a Mayta para su aventura revolucionaria. "Yo quería escribir algo sobre ese evento, y creo que en ese momento, en 1962, lo que tenía en mente era una novela política de aventuras - contar una historia en la que un puñado de personas son lo suficientemente locas, generosas o idealistas para intentar una revolución. Esa era mi primera idea" (p. 148).

Pero esa primera idea sería desechada. Explica el autor: "Yo nunca comienzo a escribir inmediatamente después de tener una idea. Mi ritmo usual es pensar durante meses y años hasta enriquecer la idea original. Entonces un día comienzo a tomar notas y a poner las anécdotas en su lugar" (p. 148). Un ritmo de añejamiento que en el caso de Historia de Mayta le llevó veinte años, porque "este plan original de la novela cambió con mi propia evolución política" (p. 148). ¿En qué consistió esta "evolución"? El autor lo explica de esta manera: "En los sesentas, mi entusiasmo por la revolución disminuyó paulatinamente, es decir, la idea de que sólo la violencia podía realmente romper el status quo y propiciar la reforma económica y social en nuestro país. Mis convicciones cambiaron y yo estaba decepcionado con Cuba y el socialismo real" (p. 148). Vargas Llosa reconoce que a medida que él cambiaba de convicciones, la idea de la revolución ganaba adeptos en su país y en Latinoamérica, al grado que "amigos [del escritor] que estaban en París regresaron a morir por su idea revolucionaria". Por eso pudo seguir "bastante de cerca lo que estaba sucediendo" con el debate sobre la revolución en Perú y "todo este material fue incorporado, consciente o inconscientemente, en mi idea original acerca de la revolución en mi país. Creo que esta mezcla de pensamientos también cambió el plan, el proyecto de la novela" (p. 149).

De lo anteriormente citado se desprenden al menos dos ideas o hipótesis. La primera es que, detrás de Historia de Mayta, sí había "un planteamiento político", no disfrazado de novela, pues Vargas Llosa es un novelista demasiado experimentado como para cometer semejante traspié, sino como planteamiento de fondo sustentador de toda la nove-

${ }^{8}$ De esa época data su sentido "Homenaje a Javier Heraud", el poeta guerrillero muerto en la selva peruana, fechado el 13 de marzo de 1963, incluido en el primer volumen de Contra viento y marea. 
la, y que por lo mismo no debería haberse sorprendido de que críticos y lectores leyeran su novela precisamente a partir, y enfatizando, ese planteamiento político de fondo: la revolución, la lucha armada, no es el camino para cambiar la sociedad peruana y, por ende, latinoamericana. La segunda tiene que ver con el timing de la escritura de la novela, que no sucedió en la primera parte de los años setenta, cuando el escritor ya tenía sus nuevas convicciones completamente asentadas, sino que esperó una década más, hasta los años 1983 y 1984, el momento en que amplios contingentes de población se habían incorporado a la lucha armada impulsada por Sendero Luminoso y el Movimiento Revolucionario Tupac Amaru (MRTA), y cuando los movimientos revolucionarios centroamericanos estaban en su apogeo. Ese es el periodo en que el escritor peruano viajó a Centroamérica, en especial a Nicaragua y El Salvador, a realizar reportajes para el periódico The New York Times y la revista Time; también fue la época en el autor formó parte de la comisión que investigó la masacre de periodistas en Uchuraccay, en los Andes peruanos, cuyo informe desató polémica. No era descabellado entonces que críticos y lectores recibieran Historia de Mayta como la respuesta política en clave literaria de Vargas Llosa a los huracanes históricos que entonces soplaban, porque en el fondo era su respuesta, aunque en el ámbito de la ficción literaria.

11. Por supuesto que un escritor con la riqueza de recursos de Vargas Llosa se mueve en varios niveles, en varias dimensiones, y era otra dimensión, no la estrictamente política, la que a él más le interesaba, la que desarrolló con mayor vigor en su charla en la universidad de Syracuse. Él mismo cuenta la génesis: “A principios de los setentas, otra idea, más importante que la idea original de una novela de aventura política, fue tomando forma: la ficción como sujeto, como tema, se convirtió en algo muy interesante e importante para mí. La ficción como algo más grande que la literatura, la ficción como algo más importante en la vida que la literatura o el arte. Descubrí que la ficción es de hecho indispensable para la humanidad, incluso para aquella gente que nunca ha leído un libro o que no está interesada en la literatura" (p. 149).

Vargas Llosa descubrió, pues, que cada ser humano necesita "incorporar en su vida real una vida ficticia" (p. 149), que esta incorporación se puede hacer a través de la literatura y el arte, o a través de otros medios como la religión o la ideología, y que este proceso puede 
producirse de manera consciente o inconsciente (p. 149). Se trata de uno de los grandes temas de la vida y la literatura: cada ser humano no es quien imagina ser y lo que vemos en cada ser humano tampoco es lo que en verdad es. Existe un universo invisible de ideas e imágenes contradictorias sobre sí mismo que cada uno porta y que en los fugaces momentos de conciencia, cuando por fin logramos percibirlo, produce una desgarradura interior; la ficción que cada uno es y que genera la ficción colectiva, de la especie. Dice Vargas Llosa: "Un día llegué a esta conclusión: que en Latinoamérica la ideología estaba cumpliendo esta tarea para mucha gente, que la ideología era el camino a través del cual esta gente incorpora la ficción en sus vidas, así como otra gente incorpora la experiencia ficticia a través de los libros de ficción, por medio de novelas o a través de ideas religiosas. Muchos jóvenes, muchos intelectuales y muchos políticos de vanguardia estaban utilizando la ideología, estaban utilizando estas ideas políticas que presumían describir la realidad, para identificar las leyes de la historia y los mecanismos de la sociedad, la evolución y el progreso, y estaban, de hecho, añadiendo a la realidad un mundo puramente imaginario. Me parece muy extraño que esta ficción, que toma el nombre de ideología política, fuera la mayor fuente de violencia y brutalidad en América Latina" (p. 149).

Si a principios de la década de los sesenta Vargas Llosa hubiera hecho este descubrimiento, de la ideología política como sostenedora de un mundo ficticio y violento, seguramente se hubiese estado refiriendo a la ideología conservadora, sustento de los ejércitos represivos y del status quo, pero como el descubrimiento lo hizo diez años después, a principios de la década de los setenta, entonces la ideología a la que se refería era el marxismo, sustento de los grupos revolucionarios y la lucha armada.

Pero lo que le interesaba no era cómo funcionaba la ideología como creadora de ficción, independientemente del bando ideológico al que se pertenezca, sino el ámbito moral de la ficción en sus dos modalidades. Lo explica así: "Pensé que era interesante cómo la ficción puede tener estas dos bases. Por un lado, la ficción puede ser benéfica para la humanidad. Los grandes logros literarios en nuestra historia, en nuestra civilización, no sólo han enriquecido a la humanidad psicológicamente sino también éticamente. Por el otro lado, la ficción ha sido un instrumento que ha producido mucho sufrimiento en la historia, porque está detrás de todas las doctrinas dogmáticas que han justificado la repre- 
sión, la censura, las masacres y los genocidios. Entonces, ¿por qué no escribir una novela acerca de estas dos facetas, el anverso y el reverso, que la ficción tiene? Cuando decidí hacer esto, la historia de Mayta, la historia de este puñado de revolucionarios, inmediatamente vino a mi mente" (p. 150).

El proceso, entonces, habría sido el siguiente: la tentación de escribir una novela de aventuras políticas con la historia de Mayta quedó guardada en la memoria del escritor, y volvió a la superficie luego de veinte años, no como respuesta directa a los acontecimientos de violencia política que estaban desgarrando al Perú y a otros países latinoamericanos, sino a consecuencia de la reflexión sobre el poder de la ficción, sobre sus maneras de filtrarse en la vida de los hombres. El impulso creativo habría sido precedido por el razonamiento moral sobre la forma buena y la forma mala de introducir la ficción en nuestras vidas. $\mathrm{Y}$ en esas circunstancias la historia de Mayta irrumpió como "la materia prima ideal para la invención de una novela en que este problema, estas dos facetas de la ficción, se materializarían y serían desarrolladas. Y ésa es la novela que creo que escribí” (p. 150). ¿Y no pudo haber sucedido de otra manera: que el repudio que producía en el autor la intensa violencia revolucionaria de esa época le generó el impulso para escribir una novela desmitificadora en la que el alzamiento de Mayta engarzaba de perlas, y que el planteamiento de las dos ficciones no era sino la forma presentable de vestir ese impulso?

12. Una vez tomada la decisión de escribir la novela, Vargas Llosa procedió de inmediato a investigar, leyó todos los periódicos y revistas de la época ("todo lo que había sido escrito"), y entrevistó a los sobrevivientes de aquel grupo trotskista y también a los participantes en la asonada. Las entrevistas le habrían ayudado no sólo a desarrollar la trama de la novela sino que lo habrían reafirmado en su planteamiento de trabajo sobre los distintos niveles en que actúa la ficción sobre las personas. Dice el autor: "Descubrí que, pese a que habían pasado de 20 a 25 años desde los hechos, la gente era reticente a hablar. Descubrí también cómo usaban sus recuerdos para justificar lo que habían hecho, algunas veces para tomar revancha de sus adversarios. Era obvio que mentían para cambiar el pasado. En otros casos, no: cambiaban inconscientemente el pasado para justificar el presente, en lo que se habían convertido. Sus declaraciones eran muy interesantes porque yo pude 
comprobar de una manera práctica cómo la ficción estaba operando ahí. La ficción era algo muy visible: lo que me decían, lo que decían recordar. Para un escritor, a diferencia de para un antropólogo o un historiador, las mentiras son tan importantes como la verdad; son igualmente útiles. Lo que importa es el mecanismo. Ésta es la ventaja del escritor sobre el académico" (p. 151).

¿Las mentiras? ¿La verdad? Una vez metidos en este mundo de ficción es válido preguntarse: ¿Hizo realmente Vargas Llosa esas entrevistas con los protagonistas del evento que luego se convertirían en personajes o es éste nada más otro recurso de su fabulación? Y en todo caso, ¿para qué necesitaba esas entrevistas? "No lo hice para estar totalmente seguro de lo que había pasado, porque yo no creo que eso sea la responsabilidad del novelista. Cuando ustedes escriben una novela no tienen la obligación de ser verdaderos y exactos: la única obligación que ustedes tienen es ser persuasivos. Lo hice no para ser objetivo, exacto, fiel a la realidad, sino, como el mismo narrador de Historia de Mayta lo dice, 'Para mentir con conocimiento de causa"' (p. 151).

Vargas Llosa es un novelista que se documenta hasta el extremo. No es difícil imaginar que, luego del titánico esfuerzo hecho para recopilar la información que le permitió escribir La guerra del fin del mun$d o$, la pesquisa realizada para la escritura de Historia de Mayta le tuvo que haber resultado muy estimulante, no sólo porque se trataba de volver a su propio país, sino porque la mayoría de los protagonistas en este caso estaban aún vivos y podría engolosinarse con el trabajo de campo. Me atrevería a decir que uno de los elementos que hace de Vargas Llosa un novelista monumental es que contiene dentro de sí a un reportero de curiosidad insaciable y a un historiador voluntarioso, gracias a los cuales consigue densidad para sus ficciones. Pero en este caso, el proceso de investigación en sí mismo se convertiría en línea narrativa y también serviría para desnudar el mecanismo de composición de una novela.

En su conferencia de Syracuse, "Transforming a Lie into Truth", el autor peruano explica que su idea era que la obra "fluyera en dos diferentes niveles" (p. 152). El primero, al que llama "nivel objetivo falso" (p. 152) de la novela, sería aquel en que el narrador, "alguien que llevaría mi nombre pero sólo para despistar una vez más al lector, trataría de recopilar material para escribir una novela sobre lo que había sucedido y cómo había sucedido" (p. 152); en este nivel, el lector encontraría "a un escritor en el proceso de recopilar materia prima, alimento para su 
fantasía, para su imaginación" (p. 152). El segundo sería un "nivel imaginario, en el que el lector seguiría el proceso de construir una ficción. El lector vería a este escritor usar lo que él sabe, lo que él lee, lo que él escucha, lo que él descubre en la realidad objetiva como material a partir del cual su fantasía e imaginación construyen una ficción, algo que no es un reflejo, ni una realidad totalmente separada (porque esta nueva realidad está usando este material todo el tiempo), pero algo que poco a poco se convierte en una historia muy diferente o más bien esencialmente diferente de lo que la fuente objetiva de la ficción es" (p. 152). La trama de la novela fue concebida, pues, como una trenza, en cuya base estaría la "continua confrontación entre estas dos dimensiones o facetas, de un proceso que tendría como protagonista al escritor en sí mismo, la mente del escritor" (p. 152).

De acuerdo con lo expresado por Vargas Llosa, Historia de Mayta arrancó entonces como una novela de tesis, de un autor que se proponía expresar su visión de mundo maniquea, basada en opuestos irreconciliables, en la que al bien y al mal correspondían dos niveles de la ficción (la literaria y la ideológica, respectivamente), y a cada uno de los dos niveles de la ficción correspondía su propia línea narrativa. Lo paradójico es que la novela habría sido concebida con la mentalidad esquemática de un ideólogo más que con la actitud de búsqueda y asombro propia de un creador. Pero, por supuesto, que en el camino las cosas fueron modificándose, al menos en lo que respecta al papel jugado por el narrador. Vargas Llosa lo cuenta: "Cuando comencé a trabajar en Historia de Mayta, mi idea era que el narrador sería un personaje invisible, sólo un instrumento, un mecanismo literario para establecer estos dos niveles distintos de la narración. Pero sucedió de diferente manera. Poco a poco el narrador fue tomando una forma más clara, adquiriendo más importancia hasta convertirse en un protagonista real. Quizá el narrador consiguió convertirse en el protagonista de la novela. Él es por lo menos tan importante como Mayta porque está manipulando lo que sucede de tal forma que lo relevante al final no es lo que sucedió sino la forma en que la realidad, los personajes y los eventos son manipulados por esta personalidad elusiva que es el narrador. Esto sucedió en la novela de una manera más inconsciente que deliberada" (p. 152).

¿Por qué sucedió esa transformación del narrador? ¿No será que un narrador invisible nos hubiera permitido ver la realidad desde el punto de vista interno de Mayta, desde su fe, sus pasiones, sus expecta- 
tivas, independientemente de los prejuicios ideológicos de un narrador que todo lo manipula? ¿No será que un narrador invisible hubiera hecho peligrar esa visión maniquea basada en opuestos? ¿Tiene el narrador en verdad una "personalidad elusiva" o se trata nada más de una versión un poco desteñida del Vargas Llosa político e ideólogo?

13. En ese mundo del bien y del mal, de opuestos irreconciliables, Vargas Llosa focaliza con claridad su idea de la ficción ideológica como el mal en Historia de Mayta: "La ficción ideológica es lo que Mayta y sus camaradas viven. Mayta es un ideólogo, un hombre totalmente convencido de que la realidad puede ser capturada por los mecanismos de la razón, por los mecanismos de una doctrina que es el marxismo, enriquecida y aumentada por Lenin y Trotsky, que ofrece todos los instrumentos para entender exactamente lo que la sociedad es" (p. 153). Vargas Llosa también tiene una idea clara de cómo esa ficción ideológica funciona dentro de la novela y cómo será percibida por los lectores, quienes serán conducidos a concluir que la ideología que representa Mayta y su círculo es negativa desde todo punto de vista: "El lector puede percibir en la novela cómo esta ideología es, de hecho, una ficción - algo que es constantemente rechazado o falsificado por la realidad objetiva-, pero a pesar de ello, Mayta tiene un mecanismo que es inmediatamente puesto en acción cuando esta falsificación de la realidad y de las ideas ocurre; y cómo la ideología inmediatamente se adapta a la nueva situación y encuentra una justificación teórica para moverse hacia adelante en la misma ruta ilusoria. Y el lector percibirá cómo todo esto conduce a Mayta y a sus seguidores hacia algo que produce exactamente el resultado y las consecuencias opuestas a lo que ellos esperan" (p. 153).

La ideología de la que está intoxicado Mayta es "negativa, tiene resultados negativos para la sociedad y para la historia cuando no es percibida como ficción, cuando es disfrazada como conocimiento objetivo, cuando se presenta como una descripción objetiva de lo que la realidad es" (p. 154). Y lo peor de esta ficción considerada como ciencia objetiva, explica Vargas Llosa, es que "impulsa a Mayta y a sus camaradas a actuar", lo que "provoca en la realidad un proceso muy destructivo porque confunde a la gente sobre lo que la realidad es y alguna veces establece una brecha entre la mente, las ideas, y las posibilidades de hacer cambios efectivos" (p. 154). 
Es interesante que Vargas Llosa no aclare en su ponencia de Syracuse si la ideología funciona como ficción "negativa" sólo en este caso porque se trata de una ideología que procede del marxismo y que lleva al sueño de la revolución, o si todas las ideologías políticas y religiosas, en la medida en que se disfrazan como conocimiento objetivo, cumplen ese papel de ficción "negativa" en la vida de los seres humanos. De ser así no habría mayor diferencia entre un revolucionario alucinado que cree cambiar la realidad como Mayta y, para dar otro tipo de ejemplo, un economista fanático que desde su gabinete gubernamental o desde un organismo internacional cree cambiar la realidad a partir de sus análisis macroeconómicos y de las políticas que de ellos se desprenden. Y, por supuesto, la pregunta es si existe una ideología política ajena a ese papel de "ficción negativa".

La "satanización" de la ideología de Mayta parece estar lograda de forma sutil en la novela, gracias precisamente a la participación activa del narrador, a su forma de organizar la información y de colar sus opiniones en el retrato de Mayta. Vargas Llosa es un viejo maestro: sabe que el instrumento más punzante para desinflar las certezas políticas e ideológicas es la sátira. Por eso al idealismo obtuso de un trotskista debe corresponder un personaje cuya personalidad esté salpicada de facetas ridículas: Mayta sufre de pies planos; huele mal; es sucio (tiene que hacer una larga fila para pasar a los sanitarios en el sitio donde vive), maricón, inadaptado, pobre de vocación, con mentalidad de catacumbas. Mayta es un antihéroe, pero a diferencia de otros antihéroes, nunca despertará nuestra simpatía.

Puedo imaginar a Vargas Llosa frotándose las manos con fruición, entre la escritura de párrafo y párrafo, feliz de haber encontrado un arquetipo de antihéroe que le permitía burlarse del arquetipo castrista encarnado por el Che Guevara: Mayta, el trotskista de catacumbas, también subió a la montaña con la intención de formar un foco guerrillero, pero lo hizo como un imbécil, sin ningún control ni la menor idea operativa sobre lo que iba a suceder, sino que su aventura estaba en manos de un joven e impulsivo teniente, inexperimentado, de oficio carcelero. Vargas Llosa llevó el juego un poco más allá, apelando a la autonomía de la ficción: arremetió contra el mito del "guerrillero heroico" de forma lateral, oblicua: si bien la asonada real tuvo lugar en 1962, el escritor la ubica en 1958, un tiempo literario anterior al triunfo de la revolución cubana. El narrador manipula los hechos para construir una 
ficción, pero ¿quién puede acusar al autor de manipularlos para reírse del modelo castrista-guevarista de lucha revolucionaria, el llamado foco guerrillero, que contaba con tantos simpatizantes en ese entonces en Latinoamérica?

14. Si la ficción ideológica, tal cual la experimenta Mayta, es el polo negativo en la novela, el polo positivo o del bien está constituido por "otra clase de ficción, una ficción que el narrador-escritor está tratando de escribir", y que el lector puede percibir como tal, como "una construcción imaginaria con algunas raíces en la realidad", que además produce, al contrario de la ficción ideológica, "resultados positivos", porque en ese mundo convulsionado "que se está cayendo a pedazos, que está prácticamente desapareciendo en una orgía de violencia, este hombre que está escribiendo encuentra una razón para resistir, para vivir", explica Vargas Llosa (p. 153). La ficción literaria, gracias a la fantasía y la imaginación, puede "ofrecer sicológicamente una manera de sobrevivir, a pesar del hecho de que en la realidad objetiva no haya ninguna esperanza" (p. 154), es decir, puede servir para la resistencia o el consuelo, como también lo hacen las religiones y las ideologías políticas, pero la diferencia radicaría en que "la ficción es positiva y útil a la sociedad, a la historia y al individuo cuando es percibida como ficción, cuando ustedes saben, mientras leen una novela o un poema, que esta idea de estar experimentando algo real es una ilusión, cuando ustedes no se sienten a sí mismos diciéndose que esto no es una ilusión sino una experiencia factual" (p. 154). Por eso, "esta ficción que es aceptada como ficción, aceptada como una ilusión, puede muy fácilmente ser incorporada en nuestra experiencia real y darnos una mejor comprensión de nosotros mismos y de lo que la sociedad es" (p. 154).

Con el ánimo de destacar esta función inequívocamente positiva que cumple la ficción literaria, Vargas Llosa lleva hasta extremos delirantes la "orgía de violencia" en que el escritor-narrador realiza su investigación sobre Mayta y construye la obra de ficción. La atmósfera en que se mueve para entrevistar a los sobrevivientes y testigos de los hechos, tanto en Lima como en el interior del país, está acechada por ejecuciones, ametrallamientos, bombazos. El clima de guerra es absoluto: se habla de una invasión de tropas cubanas y bolivianas, por un lado, y de tropas estadounidenses, por el otro. Sin embargo, Vargas Llosa es cauto, y se abstiene de llamar por su nombre a las organizaciones gue- 
rrilleras que asolaban el Perú en momentos en que él escribía Historia de Mayta; es un autor que cree en la historia y sabe que mencionarlas les otorgaría una existencia literaria que él de ninguna manera quiere darles. Pero algo parece no funcionar en esta línea narrativa: el escritornarrador se mueve con total soltura, con una absoluta falta de miedo y precauciones, como si fuese invulnerable, invisible, como si la muerte no pudiera tocarle mientras camina en medio de los tiroteos, los retenes militares, los bombardeos. Este elemento, la ausencia de miedo y paranoia en el escritor-narrador, le resta verosimilitud al relato. ¿Lo hizo a propósito Vargas Llosa? ¿Forma parte de su intención de transmitirle al lector la idea de que está leyendo una ficción? Pareciera que sí. Primero, porque un error en el nivel de la verosimilitud es poco probable en un novelista como Vargas Llosa; segundo, porque el cierre de la novela culmina el juego de la ficción dentro de la ficción que tanto apasiona al autor.

16. En su conferencia de Syracuse, Vargas Llosa explica el significado de esa "vuelta de tuerca" que experimenta el relato en su último capítulo. Las cosas habrían sucedido de la siguiente manera: cuando ya estaba finalizando la novela, el autor se habría encontrado finalmente con el Mayta real, de carne y hueso, un hombre enfermo de los riñones, avejentado, gris, que trabajaba en una heladería de Lima, al parecer alejado de toda actividad política. Luego de ese encuentro, Vargas Llosa comprendió que debía incluir esa conversación con el Mayta real como cierre de la novela. En la larga conversación, relatada por el escritornarrador, el lector descubre que Mayta ha olvidado la mayor parte de la historia del alzamiento, que él es un hombre totalmente diferente del Mayta que el narrador ha inventado. El narrador-escritor nos enfrenta entonces con tres personas bajo el nombre de Mayta: "El Mayta histórico es una persona, el Mayta sobre el que ha estado escribiendo es otra persona, y el Mayta real es aún otra persona, una tercera persona, alguien que aparece únicamente en el último capítulo de la novela como la confirmación extrema de la presencia de la ficción en el mundo en el que el narrador ha estado operando" (p. 157). Vargas Llosa insiste en la importancia de este capítulo final, porque "cambia por completo la idea de la historia que tiene el lector" (p. 157), quien experimenta la sensación de "ser separado de la realidad objetiva" (p. 157) y comprende que 
la novela lo "ha estado empujando poco a poco hacia un mundo imaginario" (p. 157). Después de la conversación entre Mayta y el narradorescritor, dice Vargas Llosa, "no hay manera ni para el lector ni para el escritor mismo de diferenciar entre el evento real y la ficción, porque todos los límites han desaparecido una vez que el escritor ha introducido al hombre real dentro de la novela. Con su testimonio, el hombre real cambia todo lo previamente descrito en el libro, no solamente el nivel ficticio de la realidad sino también cualquier cosa que el lector haya pensado que era la realidad objetiva en la novela - hasta la vasta documentación que también se convierte en ficción, en invención" (p. 157).

El momento culminante en la conversación entre Mayta y el narrador sucede cuando éste le cuenta a aquél con qué rasgos de personalidad lo ha inventado en la novela; es el momento en que la piedra angular de todo el edificio narrativo es removida y se desmoronan todas las certezas sobre realidad y ficción:

—El personaje de mi novela es maricón —le digo, después de un rato.

Levanta la cabeza como picado por una avispa. El disgusto le va torciendo la cara. Está sentado en un sillón bajito, de espaldar ancho, y ahora sí parece tener sesenta o más años. Lo veo estirar las piernas y frotarse las manos, tenso.

—iPor qué? - pregunta, al fin.

Me toma de sorpresa: ¿acaso lo sé? Pero improviso una explicación.

- Para acentuar su marginalidad, su condición de hombre lleno de contradicciones. También, para mostrar los prejuicios que existen sobre este asunto entre quienes, supuestamente, quieren liberar a la sociedad de sus taras.

$\mathrm{Su}$ expresión de desagrado se acentúa. Lo veo alargar la mano, coger el vaso de agua que ha colocado sobre unos libros, manosearlo y, al advertir que está vacío, volverlo a su sitio.

- Nunca tuve prejuicios sobre nada. Pero, sobre los maricas, creo que tengo. Después de haberlos visto. En el Sexto, en el Frontón. En Lurigancho es todavía peor ${ }^{9}$.

Esta escena final tiene una función semejante al mecanismo del "distanciamiento" brechtiano en el teatro, que busca que el espectador sea consciente, gracias a esa "distancia", de estar viendo una obra

${ }^{9}$ Mario Vargas Llosa, Historia de Mayta, en Obras completas III, p. 1134. 
teatral. Al desmentir la homosexualidad de Mayta, quizá su faceta más controvertida, se acentúa al máximo el carácter de irrealidad en el texto. Y seguramente ese guiño del narrador, al reconocer que no sabe por qué convirtió a Mayta en un personaje maricón, no lo podría hacer Vargas Llosa, quien sí debía saber por qué Mayta, el personero de la revolución y la lucha armada, es un maricón solapado, como antes (en Conversación en La Catedral) lo fue Fermín Zavala, el representante del gran capital aliado con los militares. ¿O fue otra jugarreta del inconsciente?

En todo caso, se trata de un cierre magistral, con el que, como el mismo Vargas Llosa explica, "confirmaba explícitamente la naturaleza literaria del libro como algo mucho más importante que todos los elementos políticos que aparecen en él"; una voltereta final con la que cerraba esa especie de estructura de matriuskas, en la que cada nivel de la ficción es encapsulado en un nivel de ficción más grande, hasta que todas las muñecas son desparramadas de un golpe en el suelo. El juego es tal que el lector tiene derecho a preguntarse si en verdad hubo en la historia peruana un alzamiento en la población de Jauja en 1962 encabezado por un teniente de apellido Vallejos y un dirigente trotskista de apellido Mayta, si en verdad Vargas Llosa entrevistó a todos los sobrevivientes de esa asonada, si en verdad hubo tal encuentro con el Mayta real. Si Vargas Llosa fuera un narrador de la misma tipología que Faulkner y Onetti, quienes despreciaban olímpicamente las obsesiones ideológicas y políticas de su tiempo, el lector no andaría equivocado al pensar que todo ha sido una mascarada, que nunca hubo semejantes sucesos ni tal proceso de investigación y entrevistas, que todo ha sido de principio a fin una ficción, un juego para burlarse de la historia. Porque al final de cuentas la novela funciona así, más allá de las intenciones del autor, como una carcajada ante la supuesta objetividad de la historia como ciencia.

17. Vargas Llosa termina su conferencia en Syracuse lamentando por última vez que "en ninguna de las reseñas, ensayos o incluso comentarios orales que he escuchado sobre mi trabajo" haya sido captada su idea sobre los dos tipos de ficción y que la obra sólo haya sido "tomada como una novela política contra la revolución, una novela que es una especie de acusación contra el marxismo y los actos revolucionarios en Latinoamérica" (p. 155). Aunque, en un gesto de despedida, acepta 
que el escritor no tiene la última palabra, que la intención del autor al escribir un libro puede ser una y la percepción del lector otra.

La verdad es que Historia de Mayta puede tener varias lecturas a la vez, complementarias, paralelas, no excluyentes: una parodia política para criticar el marxismo y la idea de la revolución en Perú y Latinoamérica; una novela sobre cómo se construye una novela; una tesis sobre cómo operan los mecanismos de la ficción en la mente del hombre y cómo la ideología juega el papel de ficción; un relato que hace mofa de la llamada "verdad histórica" y que desnuda su vulnerabilidad. Estas posibles lecturas, y otras más, revelan la gran riqueza de esta novela y van más allá del pensamiento maniqueo expresado por su autor en Syracuse. Las grandes obras de arte rebasan a su autor y también sus propósitos y su afán de explicaciones. Es el caso de esta novela, a la que Vargas Llosa califica como "una metáfora de mi vocación de escritor", y en la que asegura haber utilizado "todas mis experiencias como escritor de ficciones". Así como su amado Flaubert dijo "Madame Bovary soy yo", Vargas Llosa podría haber dicho "Mayta soy yo". Pero lo que dijo, al final de su conferencia en Syracuse, es que "la historia de Mayta es mi propia historia de un escritor escribiendo ficciones. Lo que el narrador hace con Mayta es lo que yo hago cada vez que escribo una novela".

\section{REFERENCIAS}

Faulkner, William. "The Art of Fiction". Entrevista de Jean Stein a William Faulkner. The Paris Review, No 12 (primavera 1956).

Vargas Llosa, Mario. Historia secreta de una novela. Tusquets Editores, 1971. - Historia de Mayta [1984]. Obras completas III. Círculo de Lectores, 2005. [Versión en inglés, The Real Life of Alejandro Mayta. Farrar, Straus and Giroux, 1986; The Noonday Press, 1998.]

- "El nacimiento de Perú". El País, 13 de abril de 1986. Recogido en MVLl, Contra viento y marea. Vol, III. Seix Barral, 1990. - Historia secreta de una novela. Tusquets Editores, 1971.

- La verdad de las mentiras: Ensayos sobre la novela moderna. Seix

Barral, 1990.

Contra viento y marea. Vol. III. Seix Barral, 1990. A Writer's Realitiy. Houghton Mififflin Co., 1991.

- "Author's Favorite" [1988]. En MVL1, A Writer's Reality. Houghton Mififflin Co., 1991.

- "Discovering a Method for Writing" [1988]. En MVL1, A Writer's Reality. Houghton Mififflin Co., 1991.

“Transforming a Lie into Truth" [1988]. En MVL1, A Writer's Reality. Houghton Mififflin Co., 1991. 